\title{
Coleta de informações em estudos sociais: abordagens quantitativas e qualitativas para analisar centros de referência de atendimento às mulheres em situação de violência
}

Maria Salet Ferreira Novellino, Rosimeri Silva de Santana Tavares

\begin{abstract}
Resumo
Introdução: Relata experiência de pesquisa que explora três diferentes abordagens metodológicas na análise de Centros de Referência de Atendimento às Mulheres em Situação de Violência com o objetivo de verificar a qualidade dos serviços prestados e identificar as práticas existentes. Método: Inicialmente definiu-se "Centros de Referência de Atendimento às Mulheres em Situação de Violência" com base em Norma específica da Secretaria Especial de Políticas para as Mulheres. Além da definição, este documento normativo descreve a estrutura e as ações desses Centros. A partir dessas definições, estabeleceram-se indicadores de análise da qualidade desses serviços. Utilizaram-se três abordagens, a saber: a abordagem quantitativa, apoiada em dados secundários retirados do Perfil dos Municípios Brasileiros (publicação do Instituto Brasileiro de Geografia e Estatística); uma segunda abordagem quantitativa, com dados primários coletados em questionário enviado por correio eletrônico a uma amostra de Centros apoiada no critério de porte do município; e abordagem qualitativa (etnográfica), envolvendo coordenadores e equipe técnica dos Centros. Resultados: A análise dos dados secundários possibilitou delinear uma visão geral dos Centros. A análise dos dados primários permitiu avançar na identificação das práticas exercidas nos Centros, embora não de forma aprofundada. 0 estudo etnográfico identificou práticas desenvolvidas nos Centros sob a percepção dos coordenadores e equipes que ali atuam. Conclusões: Os cruzamentos e complementações das abordagens quantitativa e qualitativa enriqueceram a coleta de dados, permitindo o aprofundamento das etapas de descrição e análise do tema proposto, o que reforça o uso de metodologias e técnicas mistas de recolha de informações em estudos na área de Ciências Sociais.
\end{abstract}

\section{Palavras-chave}

Indicadores sociais. Estudos sobre mulheres. Estudo etnográfico. Violência contra as mulheres. Centros de atendimento à mulher.

\section{Introdução}

O propósito deste artigo é relatar uma experiência de pesquisa realizada com o apoio do Conselho Nacional de Desenvolvimento Científico e Tecnológico/Secretaria Especial de Políticas para Mulheres $\left(\mathrm{CNPq} / \mathrm{SPM}^{1}\right)$, a qual é voltada para a identificação e análise de aspectos de atendimento em Centros de Referência de Atendimento às Mulheres em Situação de Violência.
Como em qualquer pesquisa científica, o primeiro passo foi buscar por documentos para conceituar tais Centros e estabelecer um modelo de análise voltado à contextualização destes na teoria sobre violência de gênero e nas ações decorrentes de políticas para as mulheres. Assim, construiu-se um arcabouço micro teórico (centro de referência) e macro teórico (violência de gênero, políticas para as mulheres).

\footnotetext{
${ }^{1}$ Processo no 402009/2010-0.
} 


\section{Marco teórico}

Definiram-se Centros de Referência de Atendimento às Mulheres em Situação de Violência de acordo com norma da Secretaria Especial de Políticas para as Mulheres - como equipamentos da política pública de prevenção e enfrentamento à violência contra as mulheres, os quais se vinculam administrativamente ao órgão gestor das políticas para as mulheres do município onde estão localizados e têm como finalidade atender mulheres em situação de violência. São espaços de atendimento psicológico, social e jurídico. Eles devem exercer o papel de articulador das instituições e serviços governamentais e não governamentais que integram a Rede de Atendimento às Mulheres em Situação de Violência. (BRASIL, 2006). Por ser um documento normativo, além desta definição são descritas a estrutura e ações desses Centros.

A partir dessa definição, estabeleceram-se indicadores para analisar a qualidade desses serviços, baseando-se no pressuposto que todos os Centros estariam vinculados a órgãos gestores de políticas para as mulheres e que seu público seria exclusivamente as mulheres em situação de violência. Estabeleceu-se que os principais aspectos a serem analisados nestes Centros, seriam a oferta de atendimentos psicológico, social e jurídico e a composição da Rede de Atendimento em cada Centro. Isto é, para que órgãos o Centro encaminharia as mulheres e que órgãos encaminhariam as mulheres para um determinado Centro.

A macro teoria forneceu as bases para definir violência de gênero assim resumida:

Os estudos sobre violência de gênero realizados sob a perspectiva feminista começaram (e continuam focando) nas esposas ou companheiras em situação de violência, tendo produzido literatura voltada para os fatores específicos da violência perpetrada contra as mulheres por seus parceiros. Metodologicamente, as análises feministas apoiam-se fortemente em dados coletados junto a mulheres fisicamente agredidas, especialmente aquelas que passaram por agências legais, hospi- tais ou abrigos. Teoricamente, enfatiza-se a tradição histórica da família patriarcal, as construções atuais da masculinidade e da feminilidade bem como as restrições estruturais que dificultam a saída das mulheres dessas relações violentas (JOHNSON, 1995, p. 284).

Tal enfoque auxiliou no estabelecimento, para fins deste estudo, de que a violência de gênero se restringiria à violência cometida pelo (ex) parceiro íntimo, ou seja, que as mulheres atendidas nos Centros viveriam este tipo de violência. $\mathrm{O}$ propósito dos Centros, por conseguinte, seria o de criar tanto condições objetivas, por meio dos atendimentos social e jurídico, como condições subjetivas, via atendimento psicológico, para que as mulheres possam sair da situação de violência.

\section{Encaminhamento do estudo e resultados}

Três diferentes abordagens metodológicas foram utilizadas para a análise de Centros de Referência de Atendimento às Mulheres em Situação de Violência em uma amostra de municípios. Essas três abordagens foram: quantitativa, apoiada em dados secundários; quantitativa, com levantamento de dados primários; e etnográfica.

\section{Características dos Centros: abordagem quantitativa}

A primeira abordagem refere-se à análise quantitativa de dados secundários, obtida no Perfil dos Municípios Brasileiros, o qual apresenta resultados de pesquisa realizada anualmente pelo Instituto Brasileiro de Geografia e Estatística (IBGE). Nesta pesquisa, as informações são coletadas utilizando-se um questionário dividido em blocos de questões respondidas por uma ou mais pessoas indicadas pela prefeitura para tal. Somente no ano de 2009 houve a inclusão de um bloco de perguntas sobre políticas de gênero.

Dentre as perguntas do questionário, selecionaram-se algumas que se referiam diretamente aos Centros (existência desse serviço nos municípios; oferecimento de atendimento por psicóloga, 
assistente social e advogada ${ }^{2}$. Essas perguntas foram apoiadas por variáveis quantitativas (idade, anos de estudo) e qualitativas (sexo, localização geográfica, questões com respostas sim/não referentes ao Centro e aos atendimentos nele feitos).

Selecionaram-se, igualmente, variáveis que permitiriam contextualizar os Centros: unidade da federação e região; porte do município onde se localiza o Centro; a existência, no município, de órgão gestor de politicas para as mulheres. Verificou-se, adicionalmente, a existência de Delegacia Especializada no Atendimento às Mulheres, de Juizado Especial de Violência Doméstica e Familiar contra a Mulher e de Defensoria da Mulher nos municípios. Pressupôs-se que tais órgãos seriam entes potenciais de uma Rede de Atendimento.

Para a seleção dos municípios realizou-se uma análise exploratória prévia da relação das variáveis com o Centro de Referência. Nessa análise, por exemplo, as variáveis "sexo", "idade" e "escolaridade dos prefeitos" foram utilizadas para desagregar os municípios com Centros de Referência dos demais. Verificou-se, todavia, que estas variáveis não implicavam em diferenças significativas entre os municípios onde existe (ou não existe) um Centro. Ou seja, as proporções dos municípios com ou sem Centro de Referência eram semelhantes. Por esse motivo, essas variáveis não foram consideradas na análise posterior. Verificou-se que havia diferença significativa entre as proporções de municípios quando estes foram desagregados por porte. As características dos Centros foram, então, comparadas pelo porte dos municípios onde estão localizados. Na sequência, tem-se o relato dos principais resultados obtidos com esta análise.

Em 4.522 (81,3\%) dos municípios brasileiros ${ }^{3}$ não há um órgão para a gestão de políticas de gênero. Nos $1.042(18,7 \%)$ municípios que dispõem de algum tipo de órgão gestor, este se caracteriza como uma coordenadoria de políticas para as mulheres subordinada a uma secretaria. Infelizmente não foi possível determinar a quais secretarias as coordenadorias estão vinculadas, pois esta informação não consta do Perfil embora, em nota, a publicação esclareça que "[a]inda que [o Perfil] não investigue a secretaria vinculada, sabe-se que, em grande parte dos casos, os temas de gênero e/ou mulheres são tratados no âmbito das secretarias de assistência social" (IBGE 2009, p. 107).

Previu-se que nos municípios de grande porte pudesse haver uma maior proporção na implementação de políticas de gênero, pois são nesses municípios que se concentram as organizações feministas e de mulheres, as quais não só demandariam por essas políticas como também teriam capacidade, conhecimento e experiência necessárias para contribuir com o desenho e implementação dessas políticas junto com as prefeituras. Além disso, a Secretaria Especial de Políticas para as Mulheres (SPM) estabeleceu, em seu II Plano Nacional, a meta de "contribuir para a criação e o fortalecimento de organismos municipais de políticas para as mulheres na totalidade dos municípios com mais de 100 mil habitantes" (BRASIL, 2008, p. 192).

Sob esta perspectiva, buscou-se verificar a existência de diferenças entre a proporção de municípios com políticas de gênero e o tamanho de suas populações. Os municípios foram categorizados em: micro (até 10 mil habitantes); pequenos (de 10.001 até 50 mil habitantes); médios (de 50.001 até 100 mil habitantes); e grandes (com mais de 100 mil habitantes) $)^{4}$.

A diferença relativa à existência de órgãos gestores de políticas de gênero - observando-se o porte dos municípios - é considerável. Apenas $11,2 \%$ dos municípios micro têm órgão gestor de políticas de gênero. Nos pequenos municípios essa proporção é um pouco maior $(18,6 \%)$. Nos municípios médios a proporção é de $38,3 \%$, ou seja, uma diferença de 20 pontos percentuais em

\footnotetext{
${ }^{2}$ As menções a profissões aqui e doravante são flexionadas no gênero feminino porque, em geral, quem trabalha nos Centros de Referência é deste sexo, pois facilita o estabelecimento de comunicação com as mulheres em situação de violência.

${ }^{3} \mathrm{O}$ Distrito Federal, embora tenha sido pesquisado pelo Perfil não está incluído nesta pesquisa porque elege governador e não prefeito.

${ }^{4}$ Do total dos municípios brasileiros, 47,85\% são micros; 41,78\% são pequenos; 5,59\% são médios; e 4,78\% são grandes.
} 
relação aos pequenos. Nos grandes municípios essa proporção é de 67,3\% (uma diferença de 56 pontos percentuais em relação aos micros). Portanto, quanto maior o município, maior a probabilidade de haver políticas de gênero.

Sob essa perspectiva, considerou-se que a distribuição seria semelhante no que diz respeito aos Centros de Referência. Há Centros de Referência em 259 (4,7\%) municípios brasileiros que possuem órgão gestor de políticas para as mulheres, o que significa que apenas $1 / 4$ dos municípios onde há órgão gestor contam com este equipamento. Assim como ocorre com as secretarias/coordenadorias, é nos municípios de grande porte que se concentram os Centros de Referência: os Centros estão presentes em $37,5 \%$ dos 272 municípios de grande porte, comparados aos 1,1\% dos 2.551 municípios micro, 3,4\% dos 2.425 municípios pequenos e 14,2\% dos 316 municípios médios (IBGE 2009), conforme o Gráfico 1.

Gráfico 1 - Proporções de municípios com órgão gestor e com centro de referência - 2009

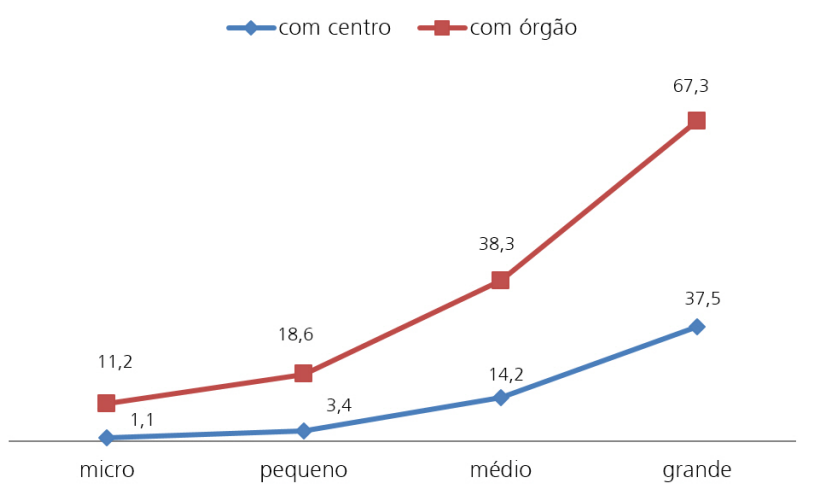

Fonte: IBGE (2009).

Os Centros de Referência devem oferecer atendimento psicológico, social e jurídico às mulheres em situação de violência (BRASIL, 2006, p. 3132). No Perfil pergunta-se se o Centro de Referência realiza atendimento psicológico, atendimento social acompanhado por assistente social e atendimento jurídico. O Gráfico 2 apresenta as proporções de Centros com esses diferentes tipos de profissionais, estratificados de acordo com os portes dos municípios onde estão localizados.
Gráfico 2 - Proporções de Centros de Referência por tipo de profissionais - 2009

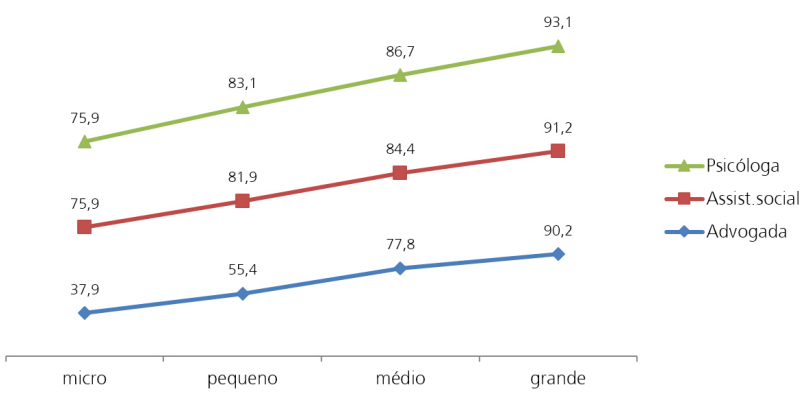

Fonte: IBGE (2009).

Nem todos os Centros oferecem atendimento especializado às mulheres em situação de violência. Como esperado, quanto maior o município maior a proporção de profissionais. A proporção de Centros com advogadas nos municípios micro, pequenos e médios - principalmente nos dois primeiros - é inferior àquelas de psicólogas e assistentes sociais. Apenas nos municípios grandes mais de $90 \%$ dos Centros contam com profissionais; ainda assim não em sua totalidade, o que seria esperado.

Como se pode observar no gráfico 2 há Centros que contam com um tipo de profissional, mas não contam com outros. Dessa constatação emerge a seguinte questão: haveria Centros sem quaisquer profissionais? Dos 259 Centros de Referência municipais existentes no país, 14 não dispõem de qualquer profissional. Assim, se por definição da Secretaria de Políticas para as Mulheres, um Centro de Referência deve oferecer atendimento psicológico, social e jurídico, então há - de fato 245 Centros no país. A distribuição dos Centros por número de profissionais pode ser visualizada no Gráfico 3.

Gráfico 3 - Distribuição dos Centros de Referência de acordo com o número de profissionais - 2009

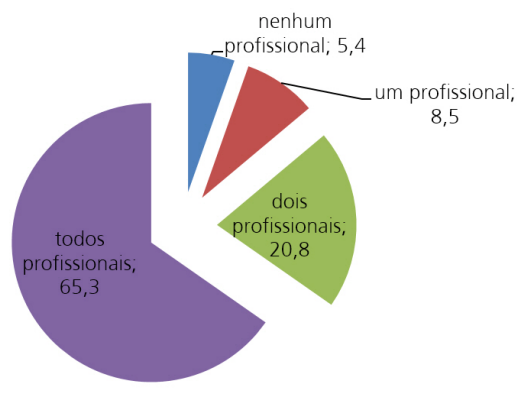

Fonte: IBGE (2009). 
Os Centros que seguem as recomendações da Secretaria de Políticas para as Mulheres, isto é, que oferecem às mulheres em situação de violência todos os tipos de atendimento (por exemplo, assistente social, psicóloga e advogada), são 169 do total de Centros; 54 oferecem dois tipos de atendimento; 22 oferecem apenas um tipo de atendimento e 14 não oferecem qualquer tipo de atendimento. Estes últimos, portanto, não poderiam ser classificados como Centros de Referência.

Não foi possível pelo Perfil verificar de qual Rede de Atendimento o Centro seria parte, se tal rede existe e qual a sua composição. Identificaram-se como entes potenciais da Rede nos municípios as Delegacias Especializadas no Atendimento às Mulheres, os Juizados Especiais de Violência Doméstica e Familiar contra a Mulher e as Defensorias da Mulher.

Contudo, o Perfil oferece uma visão geral, pois indaga sobre a existência tanto do Centro, quanto dos profissionais. Procedeu-se uma coleta direta de dados de forma a ampliar o entendimento do objeto considerando-se a qualidade dessa existência. A vantagem de trabalhar com dados secundários provenientes do Perfil foi que esses já haviam sido levantados, tinham cobertura nacional, alto grau de confiabilidade e eram de acesso público. A desvantagem foi que a análise limitouse ao que foi perguntado e respondido. De forma a coletar informações consideradas importantes foi necessário extrapolar essa fonte realizando-se a uma coleta primária de dados.

\section{Características adicionais dos Centros: abordagem quantitativa}

Para se conhecer um pouco mais os Centros de Referência de Atendimento às Mulheres em Situação de Violência procedeu-se o levantamento de informações com o auxílio de questionário enviado por correio eletrônico. Selecionaram-se, a partir do Perfil dos Municípios Brasileiros, aqueles onde havia ocorrência de tais Centros, inde- pendente da existência de coordenadoria/secretaria de políticas para as mulheres.

Embora a SPM (BRASIL, 2006, p. 28) afirme que os Centros de Referência vinculam-se administrativamente ao órgão gestor das políticas para as mulheres do município onde estão localizados, em vários municípios os Centros de Referência não estão sob as coordenadorias/secretarias de políticas para as mulheres, mas sob as secretarias de assistência social. Por este motivo, selecionouse, a partir do Perfil, os municípios onde havia Centro de Referência independente da existência de um órgão gestor de políticas para as mulheres. Essa variável era importante na análise para verificar se havia diferenças significativas na gerência por um órgão específico de políticas para as mulheres em relação a um órgão da assistência social.

Distribuíram-se os municípios que abrigavam Centros de Referência pelo tamanho de sua população e foram separados aqueles localizados nos 130 grandes municípios (com população superior a 100 mil habitantes). Desses, eliminaramse quinze devido à dificuldade de estabelecer contato (nem por telefone nem por correio eletrônico). Foram eliminados outros 37 com base na informação de funcionários destas instâncias municipais de que não havia Centro de Referência nesses municípios ${ }^{5}$. Foram também eliminados cinco municípios cujos Centros estavam subordinados aos governos estaduais, pois esta pesquisa está orientada para políticas municipais. Restaram então 73 municípios, para os quais foram enviados questionários elaborados com o propósito de levantar informações básicas sobre os Centros, tais como: subordinação do Centro, data de criação, formação da pessoa responsável, se havia atendimento psicológico, jurídico e por assistente social, o número de mulheres atendidas em 2011 e quantas delas haviam sido encaminhadas a Casas-Abrigo, assim como os órgãos que haviam encaminhado as mulheres para o Centro. Desses 73 municípios, 50 (68,5\%) responderam.

\footnotetext{
${ }_{5}^{5}$ Desses 37 municípios, em 19 deles não havia mesmo qualquer serviço. Em outros 18, as mulheres em situação de violência eram atendidas nos Centros de Referência Especializado de Assistência Social (CREAS). Esta possibilidade consta do II Plano de Políticas para as Mulheres. Em um deles, as mulheres eram atendidas em um serviço criado para todas as vítimas de violência do município.
} 
Nesse questionário foram inseridas questões julgadas relevantes e centrais a partir da literatura estudada e dos dados secundários analisados. A ideia de elaborar um questionário breve justificou-se pela percepção de que a facilidade de seu

Gráfico 4 - Distribuição geográfica dos Centros analisados - 2012

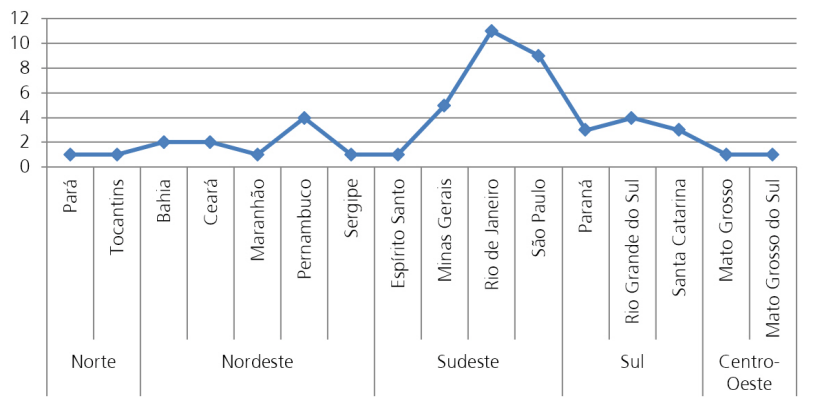

Fonte: as autoras.

preenchimento aumentaria a probabilidade de retorno, o que efetivamente aconteceu.

Os Centros de Referência analisados estão assim distribuídos (Gráfico 4): dois na Região Norte, dez na Nordeste, 26 na Região Sudeste, dez na Região Sul e dois no Centro-Oeste. Na Região Norte, um está localizado no Pará e outro em Tocantins. Na Região Nordeste, a UF com o maior número de Centros é Pernambuco (quatro), seguido por Bahia e Ceará com dois e Maranhão e Sergipe com um. Na Região Sudeste, o Rio de Janeiro é a UF com o maior número (11) de municípios, seguido por São Paulo (9) e Minas Gerais (5); no Espírito Santo apenas um ${ }^{6}$. Na Região Sul, os Centros estão assim distribuídos: quatro no Rio Grande do Sul, e três no Paraná e também em Santa Catarina. Somente nas Regiões Sudeste e Sul há ocorrência de Centros em todas as UFs.

Os Centros foram classificados por data de fundação em três grupos. Os períodos das duas últimas classes correspondem aos períodos dos mandatos das(os) prefeitas(os). O intervalo da primeira classe é maior, pois as ocorrências neste período são baixas: um Centro por ano em 1990, 1991, 1996, 1998, 2001 e em 2004; dois em 1993, 2002 e 2003; e quatro em 2001. Este é o período que antecede à criação da SPM, que aconteceu em 2003.

Os primeiros Centros de Referência criados por governos municipais foram os das cidades de São Paulo (1990), Diadema, SP (1991), Londrina, PR e Volta Redonda, RJ (1993), Belo Horizonte, MG (1996) e Barra Mansa, RJ (1998).

O segundo grupo de Centros (inaugurados entre 2005 e 2008) representam quase a metade do total de Centros existentes nos grandes municípios analisados. Em números absolutos eles são 24, sendo que desses dez foram criados em 2006 (data de promulgação da Lei Maria da Penha ${ }^{7}$ ). No terceiro grupo, os onze Centros foram criados durante o mandato atual dos executivos municipais. Esses dados indicam que os Centros analisados mostram a estabilidade dessa política e que a criação da SPM, bem como a sanção da LMP, contribuíram para o incremento das políticas municipais de gênero.

Outro aspecto considerado no questionário foi a distribuição dos Centros em relação aos órgãos aos quais estavam subordinados. Essa é uma variável importante, pois o pressuposto deste estudo é que se um Centro está sob a coordenação de uma secretaria/coordenadoria de políticas para as mulheres, maior seria o comprometimento com questões de gênero. Portanto, se um Centro estiver subordinado a secretarias de assistência haveria uma maior probabilidade de prevalecer uma concepção de assistência em detrimento de uma concepção de gênero. Resumindo, sob uma ótica feminista, as mulheres estariam em primeiro plano; e, sob uma ótica da assistência social, as famílias estariam em primeiro plano.

Muito embora, segundo a SPM (BRASIL, 2006, p. 28), os Centros estejam vinculados "administrativamente ao órgão gestor das políticas para as mulheres do município onde estão localizados", $42 \%$ dos Centros analisados subordinam-se a secretarias de assistência social. Desses 21 Centros, apenas dois estão em municípios onde não

\footnotetext{
${ }^{6}$ O Estado de São Paulo apresenta número menor de Centros do que o Rio devido a diferenças no retorno: dez municípios paulistas não devolveram o questionário; no Rio foram seis; e em Minas Gerais, dois.

${ }^{7}$ Lei n ${ }^{\circ} 11.340 / 2006$, que cria mecanismos para coibir a violência doméstica e familiar contra as mulheres.
} 
há órgão gestor de políticas para as mulheres; os outros dezenove estão em municípios onde, segundo o Perfil, há coordenadorias (Gráfico 5). É provável que essas coordenadorias não assumam os Centros, pois não contariam com orçamento Gráfico 5 - Distribuição dos Centros de Referência por órgão de subordinação

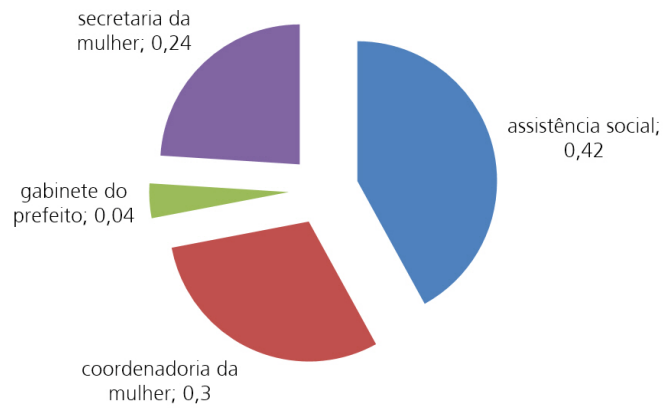

Fonte: as autoras.

próprio. Que fariam então essas coordenadorias? Provavelmente ações isoladas e episódicas como eventos e manifestações.

A formação da maior parte das Coordenadoras dos Centros é em Serviço Social (34\%). Bacharéis em Psicologia aparecem em menor proporção (16\%), seguidas de Bacharéis em Direito e em Pedagogia (12\%). O número de ocorrências na categoria 'outros', que abrange as categorias com frequências baixas ou que não foram devidamente informadas é significativa (26\%).

As assistentes sociais se apresentam em maior proporção em todos os tipos de órgão, mas a sua concentração é maior $(47,4 \%)$ nos municípios onde Centros estão subordinados a secretarias de assistência social. Nas coordenadorias da mulher, em parte significativa subordinadas a secretarias de assistência social, a proporção de assistentes sociais é significativamente maior do que nas secretarias da mulher, nas quais há uma distribuição mais equilibrada das diversas formações. Ainda assim, há um ligeiro predomínio das assistentes sociais. Pode-se especular se a subordinação do Centro, assim como a formação das suas coordenadoras, pode exercer influência na forma de abordar a violência de gênero.

Uma questão levantada referia-se a existência, nos Centros, do conjunto de profissionais das áreas do serviço social, psicologia e direito, tal como estabelecido no Termo de Referência da SPM.

Nesse particular, distribuíram-se os Centros pela quantidade de profissionais no seu quadro. Com o quadro completo, isto é, com psicóloga, assistente social e advogada, estão $80 \%$ dos Centros; com psicóloga e assistente social, 14\%; com psicóloga e advogada, $4 \%$. Um Centro conta apenas com psicólogo. Portanto, a maior parte (40 entre 50) dos Centros conta com todos os profissionais previstos no Termo de Referência. Ainda assim há dez Centros que não seguem o estabelecido pela SPM.

A questão seguinte relacionava-se com o número de mulheres que recorreram aos Centros de Referência durante o ano anterior. Esta questão teve o propósito de medir a abrangência do atendimento e, consequentemente, a importância do Centro no município.

Considerando que os Centros de Referência funcionam de segunda à sexta-feira, dividiram-se os atendimentos realizados no ano de $2011 \mathrm{em}$ classes: a primeira classe (com até 240 mulheres atendidas) representaria até um atendimento por dia; a segunda classe, de uma a duas mulheres por dia; a terceira classe compreendeu de duas a três mulheres por dia; a quarta classe de quatro a cinco mulheres por dia; e a quinta classe os Centros onde foram atendidas de cinco a mais mulheres por dia.

Na primeira classe de atendimento (240 mulheres/ano), a maior parte dos municípios atendeu um número significativamente menor. Alguns Centros atenderam menos do que uma centena, tais como Aracaju (SE), Itapipoca (CE), Joinville (SC), Petrópolis (RJ) e Sinop (MT). A explicação desse baixo atendimento não estaria na Região, pois tais Centros estão distribuídos por quase todas as Regiões, à exceção da Norte (a qual é uma Região com baixa ocorrência de Centros de Referência). A explicação também não estaria no tamanho da população feminina, que varia de 55.534 a 305.665 nestes municípios, tampouco nos tipos de atendimento oferecidos, pois há ad- 
vogada, psicóloga e assistente social em dois deles e psicóloga e assistente social em três deles. A explicação poderia estar na subordinação do Centro, pois quase todos eles, à exceção de Petrópolis, são subordinados a Secretarias de Assistência Social ou equivalente.

$\mathrm{Na}$ segunda classe, quase $60 \%$ dos Centros atendem até duas mulheres por dia. É certo que uma mesma mulher pode demandar três tipos de atendimento diferentes em um mesmo dia, caso seja atendida pela psicóloga, pela assistente social e pela advogada. Ainda assim, a demanda pode ser considerada baixa. Pertencem à terceira classe $16 \%$ dos Centros analisados, enquanto que na quarta classe $14 \%$, e na quinta, $12 \%$ dos Centros. Para verificar o alcance dos atendimentos dos Centros, relacionou-se a população feminina dos municípios com a população feminina atendida nos Centros. A Tabela 1 apresenta a relação entre mulheres atendidas e população feminina dos municípios, segundo o Censo Demográfico de 2010, agregada em três classes: até 0,5\% da população feminina passou pelos Centros em 2011; até $1 \%$ da população feminina passou pelo Centro no mesmo período; e mais de $1 \%$ da população feminina passou pelo Centro em 2011.
Quanto às Regiões, a maior parte dos Centros atendeu até $0,5 \%$ da população feminina, mas com algumas variações significativas: $100 \%$ na Centro-Oeste, quase $90 \%$ na Nordeste, em torno de $80 \%$ na Sul e Sudeste e abaixo de $70 \%$ na Norte. Alguns Centros atenderam de 0,5\% a 1\% da população feminina dos municípios. Porém, os números relativos e absolutos significativos concentram-se na Região Sudeste. Com atendimentos superiores a $1 \%$ da população feminina, há uma ocorrência nas Regiões Nordeste, Sudeste e Sul e nos seguintes municípios: Camaçari, BA, Caxias do Sul, RS e Taboão da Serra, SP.

Quanto à subordinação, os três municípios acima mencionados - que atendem a mais de $1 \% \mathrm{da}$ população feminina - respondem à coordenadorias/secretarias de políticas para as mulheres. Todos eles oferecem todos os tipos de atendimento tal como previsto no termo de referência da SPM.

$\mathrm{Na}$ última questão analisada, relativa à Rede de Atendimento, esta foi dividida em duas: a Rede de Proteção, composta pelos órgãos municipais e a Rede de Enfrentamento, composta por órgãos de segurança pública e do judiciário. Praticamente todos os Centros analisados (em torno de 90\%) recebem mulheres encaminhadas por órgãos das

Tabela 1 - Relação entre mulheres atendidas e população feminina dos municípios por Região, subordinação do Centro e profissionais - 2012

\begin{tabular}{|c|c|c|c|c|c|c|c|}
\hline \multirow[b]{2}{*}{ Região } & \multirow[b]{2}{*}{ N... } & \multicolumn{2}{|r|}{$<=, 50$} & \multicolumn{2}{|c|}{$, 51-1,00$} & \multicolumn{2}{|r|}{$1,01+$} \\
\hline & & 2 & $66,70 \%$ & 1 & $33,30 \%$ & 0 & $0,00 \%$ \\
\hline & NE.. & 8 & $88,90 \%$ & 0 & $0,00 \%$ & 1 & $11,10 \%$ \\
\hline & $\mathrm{SE} \ldots \ldots \ldots \ldots \ldots$ & 20 & $76,90 \%$ & 5 & $19,20 \%$ & 1 & $3,80 \%$ \\
\hline & S....... & 8 & $80,00 \%$ & 1 & $10,00 \%$ & 1 & $10,00 \%$ \\
\hline & $\mathrm{CO} \ldots \ldots \ldots \ldots \ldots \ldots \ldots$ & 2 & $100,00 \%$ & 0 & $0,00 \%$ & 0 & $0,00 \%$ \\
\hline \multirow[t]{4}{*}{ Subordinação } & assistência social... & 17 & $81,00 \%$ & 4 & $19,00 \%$ & 0 & $0,00 \%$ \\
\hline & coordenadoria da mulher............ & 13 & $86,70 \%$ & 0 & $0,00 \%$ & 2 & $13,30 \%$ \\
\hline & gabinete do prefeito.... & 2 & $100,00 \%$ & 0 & $0,00 \%$ & 0 & $0,00 \%$ \\
\hline & secretaria da mulher.... & 8 & $66,70 \%$ & 3 & $25,00 \%$ & 1 & $8,30 \%$ \\
\hline \multirow[t]{5}{*}{ Profissionais } & psicóloga, ass. social, advogada. & 30 & $75,00 \%$ & 7 & $17,50 \%$ & 3 & $7,50 \%$ \\
\hline & psicóloga, ass. social.... & 7 & $100,00 \%$ & 0 & $0,00 \%$ & 0 & $0,00 \%$ \\
\hline & psicóloga............. & 1 & $100,00 \%$ & 0 & $0,00 \%$ & 0 & $0,00 \%$ \\
\hline & ass. social, advogada.................. & 0 & $0,00 \%$ & 0 & $0,00 \%$ & 0 & $0,00 \%$ \\
\hline & psicóloga, advogada.................. & 2 & $100,00 \%$ & 0 & $0,00 \%$ & 0 & $0,00 \%$ \\
\hline
\end{tabular}

Fonte: as autoras. 
secretarias municipais de assistência social ou da saúde, e 22\% dos Centros receberam mulheres encaminhadas por órgãos das secretarias municipais de educação. Pelos números acima, pode-se inferir que os Centros analisados estão adequadamente articulados em termos da Rede de Proteção.

Um pouco mais de $90 \%$ dos Centros estão articulados em Rede com Delegacias da Mulher ou Delegacias Civis. Do total de Centros analisados 26\% se articulam com órgãos de segurança e também com o judiciário. Quatro dos Centros não fazem parte de uma Rede de Enfrentamento. Com base nos dados, a Rede se constitui majoritariamente pelo Centro e pelas Delegacias e a participação do judiciário na Rede de Enfrentamento precisa ser estimulada, o que pode ser feito pela criação de Juizados da Violência Doméstica nos municípios.

Os Centros de Referência foram também distribuídos em quatro classes relativas à proporção de mulheres atendidas que foram encaminhadas a Casas-Abrigo: nenhum Centro; até $10 \%$ dos Centros; entre $10 \%$ e $20 \%$ dos Centros; e mais de $20 \%$ dos Centros. Metade dos Centros (50\%) encaminhou, em 2011, até 10\% das mulheres atendidas para Casas-Abrigo. Três Centros informaram ter encaminhado mais de $20 \%$ das mulheres atendidas.

\section{As práticas dos Centros: abordagem etnográfica}

Após a análise dos 50 questionários respondidos pelas coordenadoras dos Centros de Referência procedeu-se a visita em alguns Centros com o objetivo de entrevistar coordenadoras e equipe técnica, visando conhecer as práticas dos Centros de Referência. Foram visitados, entre março e julho de 2011, dez dos Centros que haviam respondido ao questionário (Bento Gonçalves, RS; Caxias, MA; Caxias do Sul, RS; Dourados, MS; Florianópolis, SC; Guarulhos, SP; Londrina, PR; Parauapebas, PA; Recife, PE; São Paulo, SP). A partir do conhecimento acumulado com leituras e análises dos dados secundários e primários, re- digiu-se um roteiro para a entrevista observando os pontos principais dos Centros. A entrevista seguiu o roteiro e foi enriquecida com outros aspectos que não haviam sido considerados anteriormente e que dependiam das características do serviço e sua conjuntura, assim como das pessoas entrevistadas.

Um estudo etnográfico compreendeu as práticas sociais como o resultado da interação entre a estrutura (os Centros, os órgãos aos quais estão subordinados e os entes das Redes) e a agência (as estratégias aprendidas, internalizadas e imaginadas por aqueles participantes da estrutura) e permitiu a análise dessas práticas sociais tais como elas se revelaram nos depoimentos daqueles agentes envolvidos. Um estudo etnográfico pode ser realizado com participação do pesquisador no cotidiano das pessoas por um determinado período de tempo, observando o que acontece, escutando o que é dito e formulando perguntas em entrevistas formais ou informais, coletando documentos, enfim, coletando os dados disponíveis os quais iluminem as questões centrais da pesquisa (O’REILLY, 2012).

Desse modo, num estudo etnográfico, a fonte de informação é o conhecimento acumulado por aqueles que vivem o fenômeno estudado, bem como o material produzido por essas pessoas, tais como procedimentos de divulgação, registros administrativos etc. $\mathrm{O}$ tempo dispendido, em média, foi de três dias em cada cidade, nos quais foram realizadas entrevistas com as pessoas que coordenavam, trabalhavam e participavam de reuniões de trabalho nos Centros. Foram visitados os Centros de qualificação e as casas-abrigo. Embora se tenha definido anteriormente o que se buscava saber em relação a um Centro de Referência, percebeu-se que em um Centro haveria mais informação do que previamente se pensava.

Um aspecto interessante no processo de entrevista do quadro de pessoal dos Centros relacionouse com a multiplicidade de visões registradas. Questões evitadas ou brevemente tocadas por algumas pessoas podem ser aprofundadas por outras. Os pontos considerados previamente relevantes foram: a conjuntura de criação e subor- 
dinação dos Centros de Referência, a estrutura e o atendimento dos Centros de Referência, e o encaminhamento para o Centro de Referência.

Os pontos que emergiram da entrevista foram: a recepção e o acolhimento que antecedem ao atendimento especializado, os grupos de mulheres, as questões das mulheres que recorrem ao Centro e que não estão no espectro da violência, $o$ atendimento por telefone, a busca ativa por mulheres em situação de violência, o acompanhamento e monitoramento das ex-usuárias do Centro, a qualificação e capacitação das usuárias e programas para o agressor.

$\mathrm{O}$ atendimento em um Centro de Referência, em geral, segue o seguinte fluxo: recepção, acolhimento ou primeiro atendimento, atendimento feito por assistente social, atendimento feito por psicóloga, atendimento feito por advogada. Ao final, se necessário, se efetivam os encaminhamentos aos entes das Redes de Proteção e de Enfrentamento.

As mulheres chegam aos Centros por demanda espontânea ou encaminhadas por órgãos da assistência social, da saúde, da educação ou ainda pelas delegacias civis ou pelo judiciário. Os Centros produzem material informativo e têm estratégias de distribuição desse material.

Na recepção, a mulher pode ter um horário agendado ou pode ser encaminhada neste mesmo dia para atendimento. A recepção, em geral, fica na entrada do Centro em local aberto. Portanto, o máximo que é feito neste momento é o preenchimento de dados em formulários e localização de prontuários. É comum as mulheres chegarem já dispostas a deporem. Porém, como neste local não há privacidade - e como quem faz este trabalho não tem uma formação técnica - a orientação é que sirvam água e café e que a recepcionista as convençam a esperar o atendimento do pessoal técnico.

O acolhimento é o primeiro contato das mulheres com o Centro. Quem recepciona deve fazer a escuta sem julgamentos de valor e, quanto mais informação conseguir, melhor essa mulher pode- rá ser atendida no que diz respeito as suas necessidades imediatas.

A assistente social faz um estudo da condição social da mulher, levanta sua necessidade imediata e de seus filhos e vê a necessidade de encaminhar para a Rede de Proteção e de Enfrentamento. A psicóloga centra-se na questão da situação de violência que as mulheres vivem, por quais motivos se mantêm nessa relação e tentam, em conjunto, delinear um plano para que as mesmas possam contornar essa situação.

Em todos os Centros visitados, a maior demanda das mulheres é por atendimento jurídico. Com relação ao este tipo de atendimento, a orientação jurídica geral alinha-se à Lei Maria da Penha, ou seja: medidas protetivas de urgência e também o acompanhamento do processo criminal. As demais questões devem ser tratadas na Defensoria Pública, para onde as mulheres são encaminhadas se necessário.

Em alguns Centros, além dos atendimentos individuais, são organizados grupos de usuárias do Centro para discussão e reflexão de questões relacionadas à violência. O propósito de tais grupos é o fortalecimento dessas mulheres pelo compartilhamento de históricos de violência bem como das alternativas que escolheram para sair dessa situação e os problemas enfrentados.

A busca ativa é o movimento da equipe do Centro de Referência para fora do espaço físico do Centro para ir de encontro a mulheres em situação de violência. Há diferentes modos de identificação dessas mulheres bem como da intervenção realizada.

A Rede na qual se insere o Centro de Referência pode se dar em três esferas distintas e complementares, que são: a Rede da própria Secretaria ou Coordenadoria da Mulher (centro de qualificação, casa abrigo), a Rede do governo municipal de apoio às mulheres e a Rede interinstitucional de enfrentamento à violência contra as mulheres. Os profissionais dos Centros também organizam e participam de atividades de prevenção da violência que são palestras e cursos de capacitação 
para os quadros dos entes das Redes, de proteção e de enfrentamento.

\section{Considerações finais}

As leituras possibilitaram definir e caracterizar Centros de Referência. A análise dos dados secundários auxiliou no delineamento de uma visão geral dos Centros de Referência, a qual compreendeu a quantidade e distribuição dos Centros e de profissionais dos Centros. A análise dos dados primários, decorrente da amostra dos Centros, a qual foi derivada do critério de seleção o porte dos municípios onde estavam localizados, possibilitou avançar no conhecimento sobre os Centros, ainda que de forma superficial, focando na existência ou não de determinados serviços. Com o estudo etnográfico foi possível conhecer as práticas desenvolvidas nos Centros bem como de ter uma visão dos Centros dada pelos que neles atuam.

Neste artigo enfatizaram-se os (três) métodos empregados para a coleta das informações sobre os Centros de Referência para Atendimento às Mulheres em Situação de Violência. No primeiro, foram utilizados dados secundários, cuja técnica, quantitativa, se resume a analisar as variáveis de uma base de dados já constituída, e selecionar aquelas que podem melhor responder às questões de pesquisa enunciadas. Foram selecionadas as variáveis e também a população sobre quem as variáveis dizem respeito; neste caso, a população era composta por todos os Centros de Referência da base. Com essas variáveis criou-se um banco de dados utilizando-se um software estatístico para a realização de cruzamentos entre as variáveis para que se possam estabelecer relações entre as mesmas e, assim, responder às questões de pesquisa. No segundo, também quantitativo, foram utilizados dados primários levantados através de questionário elaborado pelas próprias pesquisadoras a partir dos resultados encontrados com a análise dos dados secundários e da identificação de pontos que mereciam maior e melhor exploração. Na terceira abordagem, de enfoque qualitativo, foram realizadas entrevistas com especialistas dos Centros que responderam ao questionário e que aceitaram participar desta fase da pesquisa. As entrevistas foram gravadas, cuja posterior análise permitiu a descrição detalhada da estrutura do Centro. Neste momento da pesquisa verificou-se a relação dos Centros com os órgãos aos quais estão subordinados e com os entes das Redes que encaminham ou recebem as mulheres e as estratégias aprendidas, internalizadas e imaginadas pelos participantes da estrutura. Os cruzamentos e complementações das abordagens quantitativa e qualitativa enriqueceram a coleta de dados, permitindo o aprofundamento das etapas de descrição e análise do tema proposto, o que reforça o uso de metodologias e técnicas mistas de recolha de informações em estudos na área de Ciências Sociais.

\section{Referências}

BRASIL. Secretaria Especial de Políticas para as Mulheres. Norma técnica de uniformização Centros de Referência de Atendimento à Mulher em Situação de Violência. Brasília, 2006. 45 p. Disponível em: <http:// www.agenciapatriciagalvao.org.br/images/stories/PDF/ violencia/normas_crams.pdf $>$. Acesso em: 2 abr. 2013.

BRASIL. Secretaria Especial de Políticas para as Mulheres. II Plano Nacional de Políticas para as Mulheres. Brasília, 2008. 237 p. Disponível em: <http://bvsms. saude.gov.br/bvs/publicacoes/II_PNPM.pdf $>$. Acesso em: 2 abr. 2013.

Instituto Brasileiro de Geografia e Estatística (IBGE). Pesquisa de informações básicas municipais: Perfil dos municípios brasileiros 2009. Rio de Janeiro, 2009. Disponível em: <http://www.ibge.gov.br/home/ estatistica/economia/perfilmunic/2009/munic2009. pdf $>$. Acesso em: 2 abr. 2013.

JOHNSON, M. P. Patriarchal terrorism and common couple violence: two forms of violence against women. Journal of Marriage and the Family, n. 57, p. 283294, May 1995. Disponível em: <http://www.jstor.org/ stable/353683>. Acesso em: 2 abr. 2013.

O'REILLY, K. Etnographic methods. 2.ed. London: Routledge, 2012. 
Information gathering in social studies: quantitative and qualitative approaches to analyze reference service centers to women in situation of violence

\section{Abstract}

Introduction: reports research experience that explores three different methodological approaches in the analysis of Reference Centers for Assistance to Women in Situations of Violence in order to verify the quality of services provided and to identify existing practices. Method: first, the "Centers of Reference Service to Women in Situations of Violence" were defined based on specific standard of the Special Secretariat of Policies for Women. This normative document also describes the structure and actions of these centers. Indicators were established to analyze the quality of the services provided by the Centers. The research were built on three concurring approaches, namely: a quantitative approach, based on secondary data taken from the Profile of Brazilian Municipalities (a publication of the Brazilian Institute of Geography and Statistics); another quantitative approach, with primary data collected with a questionnaire sent by email to a sample of centers chosen by the criteria of size of municipality; and a qualitative (ethnographic) approach, involving engineers and technical staff of the Centers Results: the analysis of secondary data enabled an outline a general overview of the Centers. The analysis of primary data allowed the identification of ongoing practices performed at the Centers, although not in depth. The ethnographic study identified practices developed in the Centers under the perception of the coordinators and staff. Conclusions: the intersections and complementation of quantitative and qualitative approaches enriched the collection of data, allowing the further development of stages of description and analysis the proposed subject, which reinforces the use of mixed methodologies and techniques to collect information on studies in the Social Sciences area.

\section{Keywords}

Social indicators. Women's Studies. Ethnographic study. Violence against women. Assistance centers for women.

Recebido em 26 de novembro de 2012

Aceito em 4 de abril de 2013

\section{Sobre as autoras:}

\section{Maria Salet Ferreira Novellino}

Bacharel em Biblioteconomia e Documentação - Universidade Federal do Estado do Rio de Janeiro (UNIRIO), Especialista em Documentação Científica, Mestre em Ciência da Informação e Doutora em Ciência da Informação - Universidade Federal do Rio de Janeiro (UFRJ). Pesquisadora titular III - Escola Nacional de Ciências Estatísticas (ENCE/IBGE).

saletnovellino@gmail.com

\section{Rosimeri Silva de Santana Tavares}

Bacharel em Estatística e Mestranda em Estudos Populacionais e Pesquisas Sociais - Escola Nacional de Ciências Estatísticas (ENCE/IBGE).

rosisst2003@hotmail.com

Como citar este artigo:

NOVELLINO, M. S. F.; TAVARES, R. S. de S. Coleta de informações em estudos sociais: abordagens quantitativas e qualitativas para analisar centros de referência de atendimento às mulheres em situação de violência. AtoZ: novas práticas em informação e conhecimento, Curitiba v. 2, n. 1, p. 10-21, jan./jun. 2013. Disponível em: <http:// www.atoz.ufpr.br>. Acesso em: 